\title{
TOLERÂNCIA AO ÓDIO RELIGIOSO: A DIALÉTICA DA PROTEÇÃO DO DIREITO À LIBERDADE DE EXPRESSÃO
}

\author{
TOLERANCE TO RELIGIOUS HATE: THE DIALECTICS OF THE \\ PROTECTION OF THE RIGHT TO FREEDOM OF EXPRESSION
}

\section{Natália Ramos Nabuco de Araújo1}

RESUMO: O presente estudo pretende abordar a dialética na proteção à Liberdade de expressão diante do discurso do ódio contrarreligioso. Com efeito, inicialmente, abordase sobre o valor da tolerância e a dificuldade de demarcar o grau de tolerabilidade que a atual democracia é capaz de suportar em casos de manifestações de ódio, intolerância e discriminação. Assim, a partir de uma avaliação minuciosa, se aborda o desenvolvimento jurídico que se adquire nas jurisdições européia e norte-americana, no tocante a relação do discurso do ódio contrarreligioso e o direito à liberdade de expressão, seus efeitos, as perspetivas de restrições neste cenário e as soluções e lógicas argumentativas concedidas em cada ordenamento.

Palavras-Chaves: Liberdade de expressão. Discurso do ódio. Tolerância. Religioso. Discriminação.

ABSTRACT: The present study intends to approach the dialectic in the protection of the Freedom of expression against the religious hate speech. Firstly, it is discurssed the value of tolerance and the difficulty of demarcating the degree of tolerability that a modern democracy is able to support in cases of manifestations of hatred, intolerance and discrimination. Thus, from a thorough evaluation, the study approaches the juridical development that is acquired in the European and North American jurisdictions, regarding the relation of the religious hate speech and the right to freedom of expression, its effects, the perspectives of restrictions in this scenario, and the solutions and argumentative logics granted in each order.

Keywords: Freedom of expression. Hate speech. Tolerance. Religious. Discrimination.

1 Mestre e doutoranda em Direito Público pela Universidade de Coimbra. E-mail: natalia.nabuco@gmail.com. ORCID: https://orcid.org/0000-0003-3435-7895. 
Sumário: 1. Introdução. 2. O valor da tolerância: entre o direito à liberdade de expressão e admissibilidade de discursos do ódio. 2. O dialético da proteção do discurso do ódio contrarreligioso: perspectivas críticas e panorama jurisprudencial Europeu e Norte-Americano. 2.1. Sistema Europeu. 2.2.. Sistema Norte-Americano. 3. Conclusão. 4. Referencias.

\section{INTRODUÇÃO}

Inicialmente, aborda-se sobre o valor da tolerância no atual contexto democrático, que desfruta de uma dificuldade no tocante ao grau de tolerabilidade ao ódio que uma democracia deve suportar, sobretudo, considerando as diferentes ordens jurídicas e culturas.

Prossegue-se com a temática a partir das teorias antagônicas defendidas pelos jus filósofos Ronald Dworkin e Jeremy Waldron, nomeadamente, sobre os limites da tolerância envolvendo a liberdade de expressão e a admissibilidade ou restrição do discurso do ódio.

Sedimentada a base dessas teorias, aborda-se a dialética da proteção do discurso do ódio contrarreligioso, no atual contexto democráticoo, que sofre com os efeitos de manifestações que tenham intenção de insultar, ofender, intimidar ou instigar à violência, ao ódio ou à discriminação religiosa.

Ponto de extrema complexidade, principalmente, pelas diversas concepções e interpretações, o presente estudo busca, com uma avaliação minuciosa, abordar o desenvolvimento jurídico que se adquire nas jurisdições europeia e norte-americana, no tocante a relação do discurso do ódio contrarreligioso e o direito à liberdade de expressão, seus efeitos e a perspetivas de restrições neste cenário.

Para tanto, inicia-se uma avaliação do sistema jurídico europeu, em que a partir das jurisprudências é possível depreender que as decisões ainda gravitam entre fundamentos de um regime de democracia militante e fundamentos de um regime absolutista, a depender do discurso e da legislação nacional em causa. 


\section{ABDCONST}

TOLERÂNCIA AO ÓDIO RELIGIOSO: A DIALÉTICA DA PROTEÇÃO DO DIREITO À LIBERDADE DE EXPRESSÃO

Ainda assim, maioritariamente, o sistema europeu reconhece a importância da liberdade de expressão para a formação de um debate público aberto, livre e plural e para manutenção do Estado democrático de direito, contudo, não reconhece a proteção pela liberdade de expressão às expressões contidas no discurso do ódio, pois apesar do direito à liberdade de expressão ser imanente ao pluralismo político, a tolerância e a abertura de espírito, este não configura um direito absoluto.

$\mathrm{Na}$ sequência, em posição contraposta, será apresentado o sistema norteamericano, que defende rigorosamente a proteção das mais diversas manifestações, para fomentar um debate livre de censura, logo, admite uma maior proteção ao discurso do ódio contrarreligioso, quando comparado aos demais ordenamentos jurídicos.

Diante destes panoramas, a partir da análise de jurisprudências serão avaliadas as soluções e as lógicas argumentativas concedidas em cada ordenamento. Neste particular, o presente estudo aborda que os limites entre a liberdade de expressão e a liberdade religiosa exigem um rigoroso trabalho de campo e de pesquisa teórica e, portanto, há que se ter cautela no tratamento do tema.

Por fim, para além de obter respostas precisas, se pretende, tecer críticas e apresentar conclusões sobre a adequação do tratamento atualmente oferecido pelos ordenamentos jurídicos modernos europeu e norte-americano.

Cumpre ressaltar que o cerne do estudo é demonstrar que cada uma das jurisdições possuem suas vantagens e desvantagens e ainda carecem de aprimoramento. O desenvolvimento neste cenário só será possível com um equilíbrio entre a liberdade de expressão e a liberdade religiosa de forma que, gradualmente, se conquiste o respeito às crenças religiosas, as diferenças, a tolerância, a igualdade e garantindo, concomitamente, uma opinião pública livre e consciente.

\section{O VALOR DA TOLERÂNCIA: ENTRE O DIREITO À LIBERDADE DE EXPRESSÃO E ADMISSIBILIDADE DE DISCURSOS DO ÓDIO}


A questão da dificuldade de definir o grau de tolerabilidade que uma democracia liberal está apta a suportar, semeia nas sociedades há anos e ainda não se mostra pacificada, apresentando posições distintas sob a perspetiva jurídica. De todo modo, para o estudo profícuo do tema proposto é imperioso que a noção de tolerância seja deslindada.

Nos dizeres de Scalon2 a tolerância exige que aceitemos pessoas e permitamos suas práticas, mesmo que desaprouvemos fortemente. A tolerância envolve, portanto, uma atitude intermediária entre aceitação incondicional e oposição irrestrita. Esse status intermediário torna a tolerância uma atitude desconcertante, que, em tese, nos obriga a controlar certos sentimentos de oposição e desaprovação. Por outro lado, isto leva a refletir, por exemplo, que se somos movidos por preconceitos raciais ou étnicos, o melhor remédio não é apenas tolerar aqueles a quem abominamos, mas deixar de abominar as pessoas apenas porque parecem diferentes ou provêm de um outro plano de fundo.

De todo modo, sob determinada ótica é possível depreender casos "puros de tolerância", como a tolerância religiosa. A aceitação generalizada da ideia de tolerância religiosa é, atualmente, amplamente reconhecida como um ideal, em que diversos ordenamentos defendem a Liberdade religiosa. Assim, para um individuo em que a questão religiosa seja indiferente, é fácil endossar a tolerância religiosa, logo, não existe a tensão de controle à oposição descrita acima. Por outro lado, para indivíduos em que a religião é uma questão de extrema importância pessoal, que desejam interferir na prática alheia ou contrariar, de forma violenta, crenças diferentes das suas, a tolerância religiosa não parece ter os mesmos efeitos, escapando, portanto, a ideia de tolerância pura.

2 Scalon, Tim. The difficulty of tolerance: Essays in political philosophy, Cambridge: Cambridge University Press, 2003, p. 187/188 
Com efeito, a tolerância deve ser abordada de forma diferente a depender do valor em causa, pois há uma diferença evidente entre o problema da tolerância de crenças e opiniões diversas, em que se coloca em causa uma compatibilidade teórica ou prática de verdades e o problema da tolerância que traduz na violência, na imposição de práticas e crenças de forma arbitrária, que implica, portanto, no preconceito e na discriminação. Portanto, as razões para defesa entre tais tolerâncias não podem ser as mesmas3.

Com efeito, é possível afirmar que o debate sobre a admissibilidade de discurso do ódio é, em grande parte, um debate sobre os limites da tolerância. Sob esta ótica, os jus filósofos Ronald Dworkin e Jeremy Waldron apresentam posições antagônicas quando se trata da implicação da proibição do discurso do ódio para a legitimidade da discussão política.

Dworkin4 defende que a ideia de eventuais limitações às manifestações de ódio em geral contraria o direito à liberdade de expressão, atingindo, por conseguinte, a legitimidade da democracia. Assim, afirma que a tolerância de um discurso odioso, de início, pode implicar um estado de vulnerabilidade da sociedade, no entanto, a longo prazo, seus efeitos se tornam melhores para o cumprimento dos objetivos que devemos estabelecer para nós mesmos, notadamente, por garantir a ampla proteção à liberdade de expressão.

Nomeadamente, no tocante ao discurso contrarreligioso, Dworkin5 sustenta que, ultimamente, as democracias ocidentais estão tendenciosas a punir o discurso que vilipende ou ofende as minorias religiosas6 e afirma que a religião é tratada de forma especial neste cenário, na medida em que as convicções religiosas das pessoas são tão centrais para suas personalidades que não devem ser convidadas a tolerar o ridículo de

3 Bobbio, Norberto. A Era dos Direitos. Trad. Carlos Nelson Coutinho. Rio de Janeiro: Elsevier, 2004, p. 86.

4 Dworkin, Ronald. Uma questão de princípio. Trad. Luis C. Borges. São Paulo: Martins Fontes, 2001, p. 523.

5 Dworkin, Ronald. Foreword to Extreme Speech and Democracy. In: Hare, Ivan. Extreme Speech and Democracy, New York: Oxford University Press, 2009, p. ix

6 Por exemplo, em 2006, o Reino Unido promulgou uma lei que proíbe a incitação ao ódio religioso e, em 2005, várias pessoas pediram a punição daqueles que publicaram desenhos animados em um jornal dinamarquês associando o Profeta Mohammed ao terrorismo e exigiu a censura dessas imagens em outros países. 
suas crenças e podem sentir um dever religioso para atacar o que eles levam para ser um sacrilégio. Neste sentido, Dworkin afirma que uma vez que não são permitidas, pela própria religião, proteções especiais para a discriminação racial e de orientação sexual, não é defensável admitir exceções à liberdade de expressão para proteção da religião. Por fim, afirma que considerando que as religiões já exigem proteção legal do sistema democrático para o seu exercício de forma livre, as religiões devem observar o princípio da democracia, e não o contrário.

Neste cenário, Dworkin parte de duas premissas relativa ao exercício da liberdade de expressão em uma democracia: (i) que os intolerantes são minorias nas sociedades democráticas e; (ii) a ausência de limitação a liberdade de expressão traduz na aprovação das regras democráticas pelos grupos que proferem discursos do ódio.

Sob este raciocínio, o filósofo afirma que não é coerente que uma maioria estabeleça leis a uma minoria intolerante, limitando a liberdade de expressão daquilo que entendem por discriminação, de forma que, para promoção de uma cultura tolerante e uma democracia firme, devem ser permitidas todas as formas de discursos, mesmo aqueles que ferem ou insultam, ao passo que, gradualmente, a minoria estigmatizada ao exercer o seu exercício à liberdade de expressão, tenha seu discurso neutralizado.

Sob o nosso entendimento, contudo, o discurso de Dworkin não deve prosperar, pois a realidade mostra que a minoria intolerante, cedo ou tarde, se transforma em uma maioria forte e consolidada, que afasta os princípios e valores de uma democracia. Logo, diante de sociedades marcadas, cada vez mais, por desigualdades sociais e econômicas, em que determinadas grupos não tem as mesmas oportunidades de acesso aos meios de comunicação e a manifestar suas ideias, as classes mais privilegiadas dominam o campo da verdade com suas ideias, interesses e necessidades. Dworkin parece acreditar na eficácia da atuação Estatal para harmonia social e educacional ou nos Tribunais para garantir o equilíbrio entre as classes e evitar que os intolerantes se tornem uma maioria e anulem a voz das minorias estigmatizadas. 
Por outro lado, na contramão do entendimento de Dworkin, Jeremy Waldron7 sustenta que para que a intolerância não afete os princípios e valores básicos da democracia, é imprescindível uma regulação que permita a restrição aos discursos do ódio.

Ao abordar a regulação do discurso do ódio, Waldron faz referência regulamentação do Canadá, da Dinamarca, da Alemanha, da Nova Zelândia e do Reino Unido, que, ainda que com certas variedades de rigor, regulam a restrição ao discurso do ódio, como no Canadá que proíbe declarações públicas de ódio capazes de conduzir para uma violação da paz, como na Dinamarca que proíbe declarações sujeitas a ameaçar, ridiculizar ou degradar um grupo, em razão de sua raça, cor da pele, origem nacional, étnica, como na Alemanha que proíbe ataques a dignidade humana dos outros, insultando, maliciosamente ou difamando segmentos da população ou como na Nova Zelândia e no Reino Unido que vedam discursos ameaçadores, abusivos ou insultantes que gerem hostilidade ou desprezem certos grupos de pessoas.

Sob esta ótica, Waldron admite que ainda que eventuais regulações sobre "discursos" possam, em um primeiro momento, parecer intervir na palavra e conversas faladas, o objetivo primordial é, na realidade, regular manifestações impressas e publicadas, que permanecem na sociedade. Por fim, o autor destaca que a regulação deve ser objetiva, de forma que não considera a intenção do agente, tampouco, o sentimento do destinatário.

Assim, Waldron afirma que para uma limitação do discurso do ódio, é forçoso realizar uma diferenciação entre a proteção à dignidade e a proteção às ofensas8. Com efeito, o autor sustenta que a distinção é em grande parte entre os aspetos objetivos ou

7 "[T] he costs of hate speech . . . are not spread evenly across the community that is supposed to tolerate them. The [racists] of the world may not harm the people who call for their toleration, but then few of them are depicted as animals in posters plastered around Leamington Spa [an Eng lish town]. We should speak to those who are depicted in this way, or those whose suf fering or whose parents' suffering is mocked by [the Skokie neo- Nazis], before we conclude that tolerating this sort of speech builds character". Waldron, Jeremy. The harm in hate speech. Cambridge: Harvard University Press, 2012. p. 7.

8 Waldron, Jeremy. The harm in hate speech. pp. $105-111$ 
sociais da posição de uma pessoa na sociedade, por um lado, e os aspetos subjetivos do sentimento, incluindo a dor, o choque e a raiva, por outro.

A dignidade está relacionada, em geral, com a forma como as pessoas são respeitadas perante a sociedade e não com a forma como elas se sentem, enquanto a ofensa é inerentemente uma reação subjetiva, tem a intenção exclusiva de machucar, ferir, prejudicar e atacar os sentimentos do outro.

Assim, proteger a dignidade fornece às pessoas a base de uma garantia geral de tratamento e respeito decentes na sociedade e indiretamente protege seus sentimentos.

A ideia de que pode ser ilegal prejudicar os sentimentos das pessoas não é incoerente, e, tem relação com os princípios legais, entretanto, não é função de leis de ódio racial ou religioso proteger contra os sentimentos feridos, mas sim, preservar certos grupos contra eventuais atos, oriundos de manifestações de ódio, que possam gerar violência na sociedade. Portanto, o ataque à dignidade está relacionado a critérios objetivos, ainda que, acessoriamente, o indivíduo sinta-se, eventualmente, ofendido ou não. Ou seja, para que a restrição a Liberdade de expressão se opere plenamente, não basta atingir somente a honra subjetiva de um determinado indivíduo, mas sim afetar seu status social, obstaculizar o seu exercício ao direito a igualdade, impedir de serem tratados como iguais nos mais diversos aspetos inseridos em uma sociedade.

Sob está perspetiva, no que concerne ao discurso do ódio contrarreligioso, é possível depreender uma violação à dignidade em manifestações de ódio contra indivíduos ou grupos que professam determinada crença, cujo intuito é causar sua inferiorização perante a sociedade. Neste aspeto, o autor cita exemplos como pessoas que são confrontadas nas ruas com sinais e placas dizendo "Muçulmanos e 11 de setembro! Não os sirva, não fale com eles e não os deixe entrar" ou "Judeus e Cães Proibidos".

Nestes casos, é possível definir como discursos do ódio, na medida em que os cartazes são capazes de enviar uma série de mensagens subentendidas aos membros das 
minorias sob ataque nos cartazes9, além de enviar mensagem para outros membros da sociedade, que não são membros da minoria estigmatizada10. Ou seja, resta evidente a violação à dignidade e o desrespeito perante a sociedade e por conseguinte, estes tipos de discursos devem ser restringidos.

Nomeadamente, com relação a diferença entre ofensa e violação à dignidade no cenário religioso, o autor sustenta que a distinção pode parecer mais delicada, considerando, sobretudo, o fato de quando as pessoas falam de "difamação religiosa", muitas vezes significa difamar a religião ou o seu fundador, e não apenas difamar seus adeptos. Neste sentido, o autor explica que no âmbito do discurso do ódio, a difamação de um grupo, diz respeito a difamação de membros individuais vulneráveis de grupos minoritários, ou seja, afeta a dignidade individual, por meio de características do grupo, e não a difamação do grupo como tal, portanto, as leis de discurso do ódio devem proteger os indivíduos, e não grupos como tais11.

Assim, conclui que temos que ter cuidado com um termo como "difamação da religião", sobretudo com seu uso por aqueles que querem ampliar o âmbito da legislação de discurso do ódio (e também com o uso dos opositores a tais leis) 12.

9 'Don't be fooled into thinking you are welcome here. The society around you may seem hospitable and nondiscriminatory, but the truth is that you are not wanted, and you and your families will be shunned, excluded, beaten, and driven out, whenever we can get away with it. We may have to keep a low profile right now. But don't get too comfortable. Remember what has happened to you and your kind in the past. Be afraid". Waldron, Jeremy. The harm in hate speech.. p. 2

10 "We know some of you agree that these people are not wanted here. We know that some of you feel that they are dirty (or dangerous or criminal or terrorist). Know now that you are not alone. Whatever the government says, there are enough of us around to make sure these people are not welcome. There are enough of us around to draw attention to what these people are really like. Talk to your neighbors, talk to your customers. And above all, don't let any more of them in". Waldron, Jeremy. The harm in hate speech.. pp. 2-3

11 "To sum up, then. Individual Christians, millions of them, are en ti tled to protection against defamation, including defamation as Christians. But this does not mean that any pope, saint or doctrine is to be protected, nor does it mean that the reputation of Jesus is to be protected (as Mary Whitehouse tried to protect it in the Gay News case).25 By the same token, individual Muslims, millions of them, are en ti tled to protection against defamation, including defamation as Muslims. But that doesn't mean that the prophet Muhammad is to be protected against defamation or the creedal beliefs of the group. The civic dignity of the members of a group stands separately from the stat us of their beliefs, however offensive an attack upon the prophet or even upon the Koran may seem". Waldron, Jeremy. The harm in hate speech. pp. 122-123.

12 Waldron, Jeremy. The harm in hate speech.. pp.. 126. 
Nesse cenário, Waldron não descarta a teoria de que o discurso do ódio gera o efeito silenciador13 nas vítimas de expressões de ódio, intolerância e discriminação, que se sentem humilhadas e desprotegidas pelo Estado. Esta teoria, portanto, exige uma regulação de tais discursos e uma intervenção corretiva do Estado14 para fortalecer a voz dos grupos sociais mais desfavorecidos e promover uma isonomia nas oportunidades comunicativas e assim gerar uma multiplicidade de manifestações e debates.

Por outro lado, o autor afirma que sob este panorama muitos países sustentariam suas leis de discurso do ódio, mesmo que não fosse se vislumbrasse tal efeito e, portanto, é indispensável reconhecer uma restrição com base no conteúdo do discurso 15, logo, vedando o discurso que seja expresso de forma abusiva, insultante ou ameaçadora, ou seja, o discurso que possui uma alta perspetiva de violência e discriminação e inclusive aquele que desvitaliza a garantia de que os indivíduos possam seguir sua vida diária e seus negócios comuns, sem medo de serem denegridos e excluídos como cidadãos subumanos ou de segunda classe 16 .

Diante do exposto, é possível depreender que o autor não é a favor da regulação que restrinja a Liberdade de expressão em razão de manifestações meramente ofensivas, mas considera a reserva da lei em "ultima ratio", ou seja, no último grau em que um discurso estaria mais apto de concretizar sua ação efetiva a restrição a Liberdade de expressão, e assim garantir, concomitantemente, a ordem social e democrática. Com efeito, afirma que a regulação do discurso do ódio deve ser feita a partir da designação

13 "the subordinated victims of fighting words also are silenced by their relatively powerless position in society. (...) the risk forces targets to remain silent and submissive", Cf. Lawrence III, Charles R. If he hollers let him go: Regulating Racist speech on Campus, Duke Law, Journal 1990. In: Words that Wound: Critical Race Theory, Assaultive Speech and the First Amendment, Mari J. Matsuda, Charles R. Lawrence III, Richard Delgado \& Kimberlé Williams Creenshaw. Westwiew Press, 1993, p. 69.

14 Machado, Jónatas, Liberdade de expressão. Dimensões constitucionais da esfera pública no sistema social. Boletim da Faculdade de Direito, Studia Iuridica 65. Coimbra Editora: Coimbra. 2002, 189.

15 Machado, Jónatas, Liberdade de expressão.. p. 147-150

16 Machado, Jónatas, Liberdade de expressão.. p. 160 
de categorias e formas de expressão que a prática mostra ter um impacto na dignidade de uma minoria vulnerável.

\section{A DiALÉtica DA PROTEÇÃo DO DISCURSO DO ÓDIO CONTRARRELIGIOSO: PERSPETIVAS CRÍTICAS E PANORAMA JURISPRUDENCIAL EUROPEU E NORTE-AMERICANO}

\subsection{Sistema Europeu}

Primeiramente, cumpre elucidar que o Tribunal Europeu dos Direitos do Homem (doravante TEDH) é respaldado por uma ampla gama de legislação envolvendo direitos fundamentais, nomeadamente o direito à Liberdade de expressão e à Liberdade religiosa17. Com efeito, os Artigos $9^{\circ}$ e $10^{\circ}$ da Convenção Europeia de Direitos Humanos (doravante CEDH), são os principais dispositivos a serem considerados neste cenário.

Assim, o Artigo $9^{\circ}$ prevê expressamente o direito de qualquer pessoa ao direito à liberdade de pensamento, de consciência e de religião, assegurando para tanto qualquer mudança e tipo de manifestação de sua religião ou crença e vedando restrições, com exceção as que, previstas na lei, constituírem disposições necessárias, numa sociedade democrática, à segurança pública, à proteção da ordem, da saúde e moral públicas, ou à proteção dos direitos e liberdades de outrem.

$\mathrm{Na}$ sequência, o Artigo $10^{\circ}$ garante o direito de qualquer pessoa ao direito à liberdade de expressão e dispõe que o exercício desta liberdade, pode ser submetido a certas formalidades, condições, restrições ou sanções, previstas pela lei, que constituam

17 Artigos $9^{\circ}$ e $10^{\circ}$ da Convenção Europeia de Direitos do Homem; Princípio 2 e 6 da Recomendação R(97)20 do Comitê de Ministros do Conselho da Europa; Artigo $4^{\circ}$ da Convenção Internacional sobre eliminação de todas as formas de Discriminação Racial; Article 20 (2) do Pacto Internacional de Direitos Civis e Políticos; a Recomendação de política ${ }^{\circ} 7$ da Comissão Europeia contra o Racismo e a Intolerância; Recomendação 1805 de 2007. 
providências necessárias, numa sociedade democrática, para a segurança nacional, a integridade territorial ou a segurança pública, a defesa da ordem e a prevenção do crime, a proteção da saúde ou da moral, a proteção da honra ou dos direitos de outrem, para impedir a divulgação de informações confidenciais, ou para garantir a autoridade e a imparcialidade do poder judicial.

Nomeadamente, para o tratamento do discurso do ódio, Richard Guevontian18 define a posição do TEDH de "jurisprudência flutuante", uma vez que suas decisões sobre o discurso do ódio permeiam entre conferir uma proteção preferencial à Liberdade de expressão, como ocorre no Sistema americano e entre impor restrições a Liberdade de expressão em benefício da proteção à dignidade da pessoa humana e à honra. Neste contexto, Guevontian proclama o obstáculo do TEDH para julgar com base no pluralismo da democracia e ainda indicar uma ordem ética comum a todos os seus membros.

Pois bem, equilibrar valores constitucionais e democráticos, como a Liberdade de expressão e a Liberdade religiosa, em uma democracia firme e plural pode não ser uma tarefa simples, exige uma estratégia eficaz do Estado contra eventuais ameaças a tais valores.

Com efeito, a partir de uma análise jurisprudencial da Corte, é possível depreender que as decisões do TEDH gravitam entre fundamentos de um regime de democracia militante e fundamentos de um regime absolutista, a depender do discurso e da legislação nacional em causa. Explica-se:

Por democracia militante, termo cunhado por Loewenstein 19 em 1930, entendese, originalmente, como um regime que se defende contra o totalitarismo e a intolerância, logo, afasta, qualquer posição antidemocrática. Assim, diante das

18 Guevontian, Richard. Direitos humanos fundamentais. In. Encontro de Direito Constitucional, 2004, XIII, Anais.São Paulo: Instituto Pimenta Bueno, 2004, p. 113 apud Meyer-pflug, Samantha Ribeiro. Liberdade de expressão e discurso do ódio. São Paulo: Editora Revista dos Tribunais, 2009. p. 187

19 Lowenstein, Karl. Militant democracy and fundamental rights. The American Political Science Review 31, n. 3, 1937, pp. 417- 432 
especificidades do extremismo contemporâneo é comum verificar o rastro da democracia militante em diversos governos, cujo objetivo central é estabelecer um adversário à sociedade democrática, definindo ações de proteção contra ele.

O artigo 17 da CEDH admite, de forma mais evidente, uma posição militante pelo Estado. Assim, ao tratar da proibição do abuso de direito estabelece que nenhuma das disposições da Convenção se pode interpretar no sentido de implicar para um Estado, grupo ou indivíduo qualquer direito de se dedicar a atividade ou praticar atos em ordem à destruição dos direitos ou liberdades reconhecidas na Convenção ou a maiores limitações de tais direitos e liberdades do que as previstas na Convenção.

De todo modo, a estratégica conferida pela democracia militante deve ser cautelosa, nomeadamente, quando envolve casos de religião, pois a Liberdade concedida aos Estado para estabelecer seus adversários no contexto da democracia militante pode ser muito subjetiva e resultar em legislações que proíbem a blasfêmia e o insulto religioso e que, por fim, privilegiam determinada religião sem um fundamento razoável.

Por outro lado, a partir da análise jurisprudencial do TEDH, é possível depreender decisões com fundamentos absolutistas, alinhadas com o argumento defendido por Dworkin que confere uma posição preferencial a Liberdade de expressão, de forma que sejam admitidos todos os tipos de discursos, inclusive os que choquam, estigmatizam e ofendam, possibilitando um espaço de debates sob uma lógica de argumento e contraargumento, ou seja, defende a ideia de conferir mais liberdade de expressão para parte atacada possa participar igualmente do debate.

Sob essa ótica vale citar o recente caso do Belkacem v. Belgium (App. №. 34367/14), de 27 de junho de 2017, que dizia respeito à condenação do candidato, líder e porta-voz da organização "Sharia4Belgium", que foi dissolvido em 2012, por incitação à discriminação, ódio e violência por comentários observados em vídeos do YouTube sobre grupos não-muçulmanos e Sharia. O requerente argumentou que nunca teve a intenção de incitar o ódio, à violência ou à discriminação, mas simplesmente procurava 
propagar suas ideias e opiniões. Ele sustentou que suas observações tinham sido apenas uma manifestação de sua liberdade de expressão e religião e não tinha sido capaz de constituir uma ameaça para a ordem pública.

O Tribunal observou que o requerente havia convidado os espectadores a dominar os não-muçulmanos, ensinar-lhes uma lição e combatê-los. O Tribunal considerou que as manifestações tinham um conteúdo marcadamente odioso e que Belkacem, através das suas gravações, tinha procurado suscitar o ódio, a discriminação e a violência contra todos os não-muçulmanos. Na opinião do Tribunal, um ataque tão geral e veemente era incompatível com os valores da tolerância, da paz social e da não discriminação subjacente à CEDH. Com referência às observações de Belkacem sobre a Sharia, o Tribunal observou que anteriormente havia decidido que a defesa da Sharia, ao invocar a violência para estabelecer, poderia ser considerada como "discurso do ódio" e que cada Estado contratante tinha o direito de se opor a movimentos políticos baseados em religiões fundamentalismo.

Por conseguinte, o Tribunal rejeitou o pedido, declarando que era incompatível com as disposições da Convenção e que o Sr. Belkacem tentou desviar o Artigo 10 da Convenção do seu propósito real, utilizando o seu direito à liberdade de expressão para fins que eram manifestamente contrários ao espírito da Convenção.

Por outro lado, cumpre destacar ainda o caso Gündüz v. Turquia (App. $n^{\circ}$. 35071/97), de 04 de junho de 2004, em que o Sr. Gündüz, líder da seita Tarikat Aczmendi, apareceu em um programa de televisão, Ceviz Kabuğu ("Nutshell"), transmitido ao vivo por um canal independente, $\mathrm{HBB}$, fazendo declarações críticas sobre a democracia, descrevendo as instituições seculares contemporâneas como "ímpios" e chamou abertamente para o seguimento da Sharia.

Em 5 de outubro de 1995, foi proferida uma acusação contra o requerente por violação aos $\S \S 2^{\circ}$ e $3^{\circ}$ do artigo 312 do Código Penal, sob o principal fundamento de que o discurso do requerente no programa de televisão havia incitado as pessoas ao ódio e à hostilidade. Com efeito, o Gündüz foi condenado a prisão por incitamento ao ódio e 
à hostilidade contra segurança do Estado, com base na intolerância religiosa. O requerente argumentou, com base no Artigo 10 da CEDH, que seu direito à Liberdade de expressão foi violado.

Ao analisar o caso, primeiramente, o TEDH citou o leading case Handyside v. Reino Unido, ao sustentar que a liberdade de expressão é aplicável não apenas a "informação" ou "idéias" que são favoravelmente recebidas, mas também àqueles que ofendem, chocam ou perturbam. Em segundo lugar, o Tribunal enfatizou a ideia de que, embora o Artigo 10 da CEDH permita a liberdade de expressão, no contexto de opiniões e crenças religiosas, existe também uma "obrigação de evitar, tanto quanto possível, expressões que são ofegantes para outros", na medida em que tal expressão não "contribui para qualquer tipo de debate público capaz de promover o progresso nos assuntos humanos". Em terceiro lugar, o Tribunal também observou, referenciando Murphy v. Ireland, a importância do contexto em que a expressão está sendo feita.

A Corte enfatizou que o valor da tolerância e respeito pela igual dignidade de todos constituem os alicerces de uma sociedade democrática e plural e, portanto, em determinadas sociedades é preciso sancionar ou vedar formas de expressão que incitam, promovem ou justificam o ódio com fundamento da intolerância, desde que quaisquer formalidades, condições, restrições ou sanções impostas sejam proporcionais ao objetivo legítimo prosseguido em relação do discurso do ódio e o incitamento à violência. Logo, formas de discursos do ódio não são protegidas pelo Artigo 10 da CEDH.

Entretanto, no caso em questão, a Corte concluiu que ainda que tais declarações constituissem idéias extremistas de sua seita e afirmasse que os valores democráticos eram incompatíveis com o conceito de islamismo, não poderiam ser consideradas como um incitamento à violência ou como um "discurso de ódio" baseado em intolerância religiosa. Ademais, o tema da discussão foi objeto de um amplo debate na mídia turca e preocupou-se com um problema de interesse geral, que não ofereciam um risco real de 
transfigurar a democracia. Com efeito, a Corte concluiu que houve uma violação do artigo 10 da CEDH e que o caso não correspondia um discurso do ódio20.

Diante dos casos analisados e de uma panorama de outras decisões relevantes da Corte21, é possível depreender que a Corte ainda não firmou uma posição linear, clara e consolidada sobre as proibições de ofensas contra religiões e grupos religiosos, nomeadamente, para determinar quando a legislação de um determinado país ofende a CEDH.

Verdadeiramente, a principal função do Tribunal é analisar se os Estados limitam o direito de forma justa e legítima e se uma determinada restrição é proporcional, justificável, legal e compatível com os requisitos mínimos do Estado de direito. Ainda que o papel da Corte seja subsidiário à dos Estados Partes para identificar uma determinada ameaça e restringir um direito, esta margem de apreciação dos Estados não lhes garante uma alimentação descontrolada, ela deve caminhar de mãos dadas com uma supervisão do TEDH.22. Essa parceria garante a prevenção de uma restrição indevida à Liberdade de expressão pois assegura uma supervisão do Tribunal e restrições mais justas. Logo, cabe a Corte proferir uma decisão final a respeito de compatibilidade de eventuais restrições ou do exercício abusivo do direito à Liberdade de expressão, com a Convenção, o que ocorre na análise de cada caso em concreto.

Contudo, diante da dificuldade da Corte para determinar quando a legislação de um determinado país ofende a Convenção, essa margem de apreciação pode gerar uma

20 O juiz Türmen, turco, ofereceu um voto dissidente ao defender que as palavras usadas pelo requerente eram um insulto grave e foram ofensivas para a maioria do povo turco que vive em uma sociedade secular, logo, correspondiam, plenamente, a um discurso de ódio.

21 S.A.S. v. França (App. $n^{\circ}$. 43835/11), de 01 de julho de 2014, Norwood v. the United Kingdom (App. $\mathrm{n}^{\circ}$. 23131/03), de 16 de novembro de 2004 e Ivanov v. Russia (App. no. 35222/04), de 20 Fevereiro de 2007, Erbakan v. Turkey (App, $\mathrm{n}^{\circ}$. 59405/00), de 06 de Julho de 2006. e ainda o célere caso de Caso Handyside v. Reino Unido (App. $\mathrm{n}^{\circ}$. 5493/72), de 07 de Dezembro de 1976.

22 Bakirciolglu, Onder. Freedom of Expression and Hate Speech. Heinonline, 16 Tulsa. J. Comp.\& Int'1 L. 2008. p. 38 
variação demasiada quando se trata de limitações de discursos, pois ocorre de acordo com os interesses, necessidades e culturas de cada Estado.

Ademais, para casos de ofensas religiosas, o TEDH deve avaliar seus artigos com maior precisão, pois a partir da leitura do Artigo 9 da CEDH, que protege a Liberdade de pensamento, de consciência e de religião, é possível depreender que somente a ideia de crença possui uma proteção plena e irrestrita, enquanto a manifestação da crença pode ser condicionada nos termos do Artigo 9 (2), CEDH23.

Com efeito, a Corte deve ter cautela em suas decisões, uma vez que existe uma diferença entre proteger um ato ofensivo contra um grupo religioso e contra uma religião, na medida que este último pode não abarcar aspetos da Liberdade religiosa.

Com efeito, a Comissão de Veneza, tem incentivado os Estados Membros a reverem suas legislações da blasfémia e de insultos religiosos. De forma geral, a "blasfémia" consiste na proibição legal de ofender, de insultar ou de mostrar desprezo ou falta de reverência por Deus e, por meio de extensão, para qualquer crença, dogma ou qualquer coisa considerada Sagrada e o "Insulto Religioso" consiste no insulto baseado em pertencer a uma religião particular" e "insulto aos sentimentos religiosos", portanto, não fazem referência, necessariamente, ao direito a Liberdade religiosa de um grupo. Assim, a Assembleia Parlamentar observou que a legislação e as práticas nacionais relativas à blasfémia e outras insultos religiosos muitas vezes refletiam a posição dominante de religiões particulares em estados individuais, logo, "em vista da maior diversidade de crenças religiosas na Europa e o princípio democrático da separação do estado e da religião, as leis de blasfémia devem ser revistas pelos Estados

23 Convenção Europeia de Direitos do Homem, Artigo 9. 1. Qualquer pessoa tem direito à liberdade de pensamento, de consciência e de religião; este direito implica a liberdade de mudar de religião ou de crença, assim como a liberdade de manifestar a sua religião ou a sua crença, individual ou colectivamente, em público e em privado, por meio do culto, do ensino, de práticas e da celebração de ritos. 2. A liberdade de manifestar a sua religião ou convicções, individual ou colectivamente, não pode ser objecto de outras restrições senão as que, previstas na lei, constituírem disposições necessárias, numa sociedade democrática, à segurança pública, à protecção da ordem, da saúde e moral públicas, ou à protecção dos direitos e liberdades de outrem. 
membros e parlamentos, de forma que a blasfémia, como um insulto a uma religião, não deve ser considerada uma ofensa criminal24.

Neste cenário, diante de uma manifestação contra uma crença ou dogma religiosos deverá ser avaliado a sua possibilidade de ofensa para a sociedade, considerando, para tanto, se a Liberdade religiosa do grupo em questão é afetada.

No tocante aos casos claros de discursos do ódio proferidos diretamente contra um grupo religioso, deverá ser avaliada a sua intenção de discriminação e incitamento a violência, questão que ainda depende da formação de uma jurisprudência linear e sólida.

A Comissão de Veneza afirma as legislações domésticas contra o discurso do ódio tem aumentado, contudo, uma definição única e firme de um incitamento ao ódio ainda não foi consolidada neste contexto, pois muitas concepções são demasiadamente amplas, colocando, por exemplo, a raça e a religião em pé de igualdade como motivos proibidos de discriminação e intolerância.

Neste sentido, a Comissão ressalta a importância de se diferenciar, um discurso do ódio baseado na raça daquele baseado na religião. "A raça é herdada e imutável, a religião não é, e é em vez disso, com base em crenças e valores que o crente tenderá a manter como a única verdade. Esta diferença levou alguns a concluir que um alcance de crítica mais amplo é aceitável em relação a uma religião do que em relação a uma raça. Este argumento pressupõe que, enquanto as ideias de superioridade de uma raça são inaceitáveis, as ideias de superioridade de uma religião são aceitáveis, pois é possível ao crente da religião "inferior" se recusar a seguir algumas ideias e até mesmo mudar para a "superior" "Religião"'’25.

Por fim, a comissão ressalta alguns aspetos para serem considerados no tratamento de discurso do ódio, nomeadamente: o contexto em que as declarações ou

24 venice commission, On the relationship between freedom of expression and freedom of religion: the issue of regulation and prosecution of blasphemy, religious insult and incitement to religious hatred, outubro de 2008, pp. $8-14$

25 venice commission, On the relationship between freedom of expression and freedom of religion. p. 14 
publicações contestadas são proferidas e se o ambiente é restrito ou amplamente acessível ao público em geral, como a internet, o público a que se dirige; se a declaração foi feita por uma pessoa em sua capacidade oficial, em particular se esta pessoa exercer funções específicas, como um político26.

Com efeito, é possível concluir que ainda que a Corte em alguns casos confira proteção as religiões, como em casos de blasfémia e, eventualmente, uma proteção a Liberdade religiosa de alguns grupos, como em casos de discursos do ódio, não são uma garantia que a Corte permanecerá atuando da mesma maneira, suas decisões carecem de um raciocínio linear, de modo a afastar a ideia de "jurisprudência flutuante". Além disso, as decisões da Corte exigem a adoção de requisitos mínimos que fundamentem o incitamento à violência de um determinado discurso e de determinar com clareza quando uma legislação doméstica afronta a $\mathrm{CEDH}$, de forma a justificar sua linha de entendimento e nortear demais casos futuros. Enfim, ainda existem muitos elementos a serem analisados pelo TEDH para que este adote uma diretriz e assuma uma posição precisa sobre proibições de discursos que ofendam religiões e grupos religiosos.

Nomeadamente, no tocante as legislações domésticas sobre incitamento ao ódio27, a Comissão de Veneza assentou que praticamente todos os Estados membros do Conselho da Europa (com exceção de Andorra e São Marino) preveem uma infração,

26 venice commission, On the relationship between freedom of expression and freedom of religion. p. 15

27 "There is no generally recognised definition of "incitement to hatred", or "hate speech". The Committee of Ministers, in its Recommendation (97)20, provides the following working definition: the term "hate speech" shall be understood as covering all forms of expression which spread, incite, promote or justify racial hatred, xenophobia, anti-Semitism or other forms of hatred based on intolerance, including: intolerance expressed by aggressive nationalism and ethnocentrism, discrimination and hostility against minorities, migrants and people of immigrant origin. The European Court of Human Rights referred to "all forms of expression which spread, incite, promote or justify hatred based on intolerance (including religious intolerance)" (Gunduz v. Turkey judgment of 4 December 2003, § 40.) Hate speech is not a so-called "hate crime". Hate crimes always comprise two elements: 1) a criminal offence committed with 2) a bias motive. As speech would not be a crime without the bias motive, it lacks the first essential element of hate crimes. However, "direct and immediate incitement to criminal acts" is prohibited in all member States: in those countries where what is penalised is not incitement to hatred as such, but incitement to violent acts or through violent acts, such incitement would qualify as a hate crime. General and specific penalty enhancements (see para 32 above) also qualify as hate crime legislation." venice commission, On the relationship between freedom of expression and freedom of religion. p. 9 
ainda que com certas variedades de rigor28. Em alguns desses países (Áustria, Chipre, Grécia, Itália e Portugal), no entanto, a lei sanciona a incitação a atos suscetíveis de criar discriminação ou violência, e não ao mero ódio.

Na maioria dos Estados membros, o tratamento da incitação ao ódio religioso29 é um subconjunto de incitamento ao ódio geral, a qual contempla o ódio racial, nacional e religioso da mesma maneira e, por vezes, o ódio contra orientação sexual, convicções políticas, linguagem, status social, deficiência física ou mental. Ademais, na maioria dos países o incitamento ao ódio deve ocorrer em público30, enquanto em outros representa um agravante31. Com relação ao caráter subjetivo, em geral, a intenção de provocar o ódio não constitui um requisito para configurar o discurso do ódio32.

Neste cenário, alguns casos como o ocorrido em 2007 ao Jornal francês Charlie Hebdo, nos obrigam a abordar os conflitos entre a liberdade de expressão e a tolerância religiosa sob a ótica das legislações domésticas. O célere caso foi marcado pela reimpressão de caricaturas de Maomé, publicados inicialmente em um jornal dinamarquês, considerado por muitos muçulmanos e demais pessoas como uma incitação à discriminação contra os franceses de origem islâmica. Organizações muçulmanas processaram o jornal por abuso religioso.

2801 ano (Bélgica, França e Holanda); 18 meses (Malta); 12 anos (Áustria, Chipre, República Checa, Dinamarca, Geórgia, Islândia, Irlanda, Lituânia, Eslovênia, Suécia); 03 anos (Azerbaijão, Bulgária, Croácia, Estónia, Hungria, Itália, Letónia, Moldávia, Noruega, Polônia, Eslováquia, Espanha e Turquia); 04 anos (Armênia); 05 anos (BósniaHerzegovina, Alemanha, Mônaco, Montenegro, Portugal, Sérvia, "ex-República jugoslava da Macedônia", Ucrânia); 10 anos (Albânia). Em todos os países, uma pena de prisão é alternativa ou cumulativa com uma multa pecuniária. venice commission, On the relationship between freedom of expression and freedom of religion. p. 10 $29 \mathrm{Na}$ Geórgia, Malta, na Eslováquia e na "antiga República jugoslava da Macedónia", a religião não está especificamente prevista como motivo de ódio

30 Com excepção da Albânia, da Estónia, de Malta, da Moldávia, do Montenegro, dos Países Baixos, da Polónia, da Sérvia, da Eslovénia e da Ucrânia e do Reino Unido. Na Áustria e na Alemanha, a incitação ao ódio deve perturbar a ordem pública para que ela se torne uma ofensa. Na Turquia, deve colocar clara e diretamente o público. Na Arménia, Azerbaijão, República Checa e Roménia o incitação ao ódio através dos meios de comunicação de massa é um agravante.

31 Armênia, Bósnia e Herzegovina, Letónia, Montenegro, Sérvia, Eslovênia, Ucrânia

32 Com exceção do Chipre, Irlanda, Malta, Portugal, Ucrânia e Inglaterra e País de Gales. 
Decorrido um polêmico debate, o Tribunal concluiu que ainda que as caricaturas fossem chocantes, provocadoras ou insultante, elas traduzem o exercício amplo da Liberdade de expressão e da Liberdade de imprensa para manifestar de forma livre uma opinião, ademais, o Charlie Hebdo não possui ampla circulação e ninguém é obrigado a adquiri-lo, ou seja, o seu alcance não é amplo e irrestrito.

Com relação aos desenhos criticados, o Tribunal destacou que somente a caricatura de Maomé com um turbante em forma de bomba poderia sugerir uma forma de violência terroristas pelos grupos muçulmanos, o que implicou no abuso do direito, contudo, o contexto em que as imagens foram proferidas mostra que a intenção no jornal não foi exclusivamente para ofender os muçulmanos, mas expor que o fundamentalismo religioso, pode perfazer atos terroristas, logo, os limites da Liberdade de expressão e religiosa não foram excedidos pelo jornal.

Atravessando a histeria dos comentários da publicação do Charlie Hebdo, em 2015, o jornal foi alvo de um ataque terrorista, em que doze pessoas foram mortas e dez ficaram feridas33. Diante do ocorrido, consolidou-se uma gama internacional de contribuintes para avaliar o impacto simbólico e político do ataque terrorista. Os ataques iniciaram um movimento contínuo para medidas de segurança e vigilância estatais cada vez mais repressivas, e alimentaram o ressurgimento da extrema direita em toda a Europa, deixando a esquerda perigosamente dividida. Por conseguinte, esses desenvolvimentos levantam questões profundas sobre os significados e limites de conceitos como o secularismo na França pós-colonial, o papel da mídia, a política de liberdade de expressão e a melhor forma de combater o racismo e a islamofobia34.

No tocante à legislação da França, a noção de laicidade encontra-se reafirmada no Artigo $1^{\circ}$ da atual Constituição de 1958, que assegura a igualdade entre todos, sem

33 Disponível em »http://expresso.sapo.pt/internacional/massacre-na-sede-de-jornal-que-publicou-caricaturasde-maome-faz-pelo-menos-12-mortos=f905151 « Acesso em 17 de janeiro de 2018

34 Titley, Gavan; Mondon, Aurélien. After Charlie Hebdo: Terror, Racism and Free Speech. Zed Books, 2017. 
distinção de origem, de raça ou de religião35, já o direito à Liberdade de expressão é protegido pelo Artigo $11^{\circ}$ da Declaração dos Direitos do Homem e do Cidadão, de 1789, cujo o efeito é constitucional.

O direito a Liberdade de expressão é regulado tanto na esfera administrativa quando penal. No âmbito administrativo existem algumas leis e códigos que regulam os discursos, incluindo os que incitam o ódio e à violência com base na raça, etnia, sexo, religião, orientação sexual, etc. Na esfera penal, a principal lei que regula os casos de discursos do ódio é a Lei sobre Liberdade de imprensa, de 29 de julho de 188136, que contempla como crime a provocação ou incitação ao ódio e à violência a uma vasta categoria de discursos (etnia, religião, crença, gênero, orientação sexual, deficiência etc.) Neste sentido, cumpre reiterar que o direito francês pune o discurso do ódio independente de sua publicação e alcance.

$\mathrm{Na}$ França a democracia e a laicidade caminham juntas, de forma que defendem veemente uma neutralidade diante da religião e de uma democracia firme. Assim, a França parece buscar um equilíbrio entre a Liberdade de expressão, lei e ordem. Contudo, esta neutralidade exige uma nova perspetiva para debater os casos de discursos do ódio nos dias atuais em que são verificados atos terroristas, a crescente multiculturalidade e de um aumento no número de refugiados, nomeadamente, de muçulmanos. Assim, o Estado Francês, com intuito de evitar maiores conflitos, tem adotado, por vezes, atos de repressão ao exercício da Liberdade religiosa, como fechar mesquitas radicais37 e proibir o uso do véu em locais públicos38. guerra-santa-6215713.html « Acesso em 17 de janeiro de 2018. Neste sentido ver o caso S.A.S. v. França (App. $\mathrm{n}^{\circ} .43835 / 11$ ), julgado pelo TEDH em 01 de julho de 2014.

38 Disponível em » https://www.publico.pt/2017/03/14/mundo/noticia/varios-paises-europeus-ja-proibiram-ouso-do-veu-integral-1765195 « Acesso em 17 de janeiro de 2018 
A proliferação de episódios de violência antissemita e a intolêrancia contra outras minorias religiosas exigem cada vez mais a adoção de medidas efetivas para combatêlas, contudo, uma mudança de perspetiva neste cenário deve ser realizada com cautela, sob pena de crescer a islamofobia, que por sua vez arrasta o extremismo, seja o islâmico ou de outras religiões e, que invariavelmente direciona novos conflitos39, como se tem verificado na Espanha em que casos de intolerância religiosa, como a islamofobia, cresceu exponencialmente no último ano40.

No caso do direito espanhol, a regulamentação do discurso de ódio antirreligioso no Código Penal espanhol varia desde a sua consideração como uma circunstância agravante (artigo 22 do Código Penal) até a recente previsão de um tipo específico de "crime de ódio" sob a nova regulamentação do crime de insultos ou provocação ao ódio e à discriminação, que inclui o ódio religioso (artigo 510 do Código Penal); atravessando a digitação do escárnio que já introduziu o Código Penal de 1995. Recentemente, os limites entre o insulto aos sentimentos religiosos e o discurso de ódio antirreligioso foram alterados após a última reforma do Código Penal de março de 2015, dificultando a identificação quando somos confrontados com um discurso insultante diante do sentimento ou do escárnio religioso (artigo 525 do Código Penal) e quando há incitamento ou provocação ao ódio por religião ou crença (artigo 510 do Código Penal). Assim, como na França, a blasfémia não é mais definida como um crime, contudo, o "insulto religioso" é contemplado na Espanha como "escárnio" (artigo 525 do Código Penal), que se traduz por "ofender os sentimentos dos membros de uma confissão religiosa, publicar, em palavras, por escrito ou através de qualquer tipo de documento,

39 Disponível em » https://www.dn.pt/opiniao/opiniao-dn/maria-joao-tomas/interior/o-crescimento-daintolerancia-religiosa-4085001.html « Acesso em 17 de janeiro de 2018

40 Disponível em » https://laicismo.org/2017/05/el-discurso-del-odio-dispara-los-casos-de-islamofobia-enespana/162948/ «Acesso em 17 de janeiro de 2018 
burla de seus dogmas, crenças, ritos ou cerimônias"; bem como aqueles que "vexam, também publicamente, aqueles que os professam ou os praticam"41.

Não obstante, mesmo com as recentes alterações legislativas, os critérios jurisprudenciais do Supremo Tribunal Espanhol ainda não possuem uma linearidade, sendo frequente distinções entre as sentenças proferidas, logo, resiste o vácuo de uma proteção firme e adequada do discurso do ódio dirigido contra as minorias.

Por exemplo, no tocante ao uso do véu em lugares públicos, a jurisprudência é contraditória, uma vez que são proferidos julgamentos favoráveis à proteção deste direito, como no caso da Suprema Corte de Justiça das Ilhas Baleares, de 9 de Setembro de 200242, bem como existem sentenças restritivas, que autorizam a sua limitação tanto no local de trabalho como no espaço público, nomeadamente, nas escolas, como no caso de Najwa Malha em 2010, em que o Tribunal de Contencioso Administrativo de Madrid emitiu um acórdão no qual alegava que a decisão do instituto de expulsar a aluna Najwa Malha por usar um véu não violou sua dignidade, pois de acordo com o tribunal, os regulamentos internos do centro educacional estavam sendo cumpridos. Por este motivo, o Tribunal Superior de Justiça de Madrid rejeitou o recurso do adolescente. Esta decisão foi rejeitada publicamente pelo Conselho Islâmico, aludindo à falta de garantia do direito constitucional à liberdade religiosa43.

Para afastar contradições, as linhas entre críticas e insultos devem ser muito bem desenhadas, o que varia entre o local e a cultura. Nos países subdesenvolvidos, muitas críticas são vistas como insultos e em países desenvolvidos muitos insultos são vistos como críticas. Portanto, as configurações desses limites exigem trabalho de campo e

41 Donaire, Juan Antonio Carrillo. Libertad de expresión y “discurso del odio" religioso: la construcción de la tolerancia en la era postsecular. Revista de Fomento Social 70. 2015. pp. 222/223

42 STSJ Islas Baleares, (Sala de lo Social, Sección1 ${ }^{a}$ ) no 457, de 9 setembro de 2002

43 Sanna, Júlia Mestres. La Islamofobia en Europa y en el Estado español: Repercusiones en el ejercicio del derecho fundamental a la libertad religiosa, 2017, pp. 44/45 
pesquisa teórica séria. No entanto, um mundo dinâmico e amadurecido só pode ser alcançado com respeito tanto às crenças religiosas quanto à liberdade de expressão44.

\subsection{Sistema Norte-Americano}

Na contramão da posição europeia, o sistema americano possui um alto grau de proteção ao direito a Liberdade de expressão, ao garantir na $1^{\circ}$ emenda da sua Constituição de 1791 que "o congresso não deverá fazer qualquer lei a respeito de um estabelecimento de religião, ou proibir o seu livre exercício; ou restringindo a liberdade de expressão, ou da imprensa; ou o direito das pessoas de se reunirem pacificamente, e de fazerem pedidos ao governo para que sejam feitas reparações de queixas".

Diante da consolidação doutrinal e jurisprudencial, é possível depreender que, maioritariamente, o direito a liberdade de expressão recebe uma proteção preferencial com relação aos demais direitos fundamentais. A justificativa para o rigor desta proteção circunda, em geral, na ideia de uma proteção sólida da democracia, na justificação do contrato social, na busca da verdade e na autonomia individual 45 .

Com efeito, Sedler afirma que sob a perspetiva da Primeira Emenda, não existe uma "má ideia" e o remédio para o mau discurso é mais discurso, de forma a garantir um debate das mais diversas questões públicas e a divulgação ampla de todas as ideias e opiniões. Assim, conclui que a Primeira Emenda protegeria o direito de um jornal publicar um desenho animado do Profeta Maomé, e também protegeria o direito das estudantes e mulheres muçulmanas de vestir o lenço da cabeça como uma forma de expressão religiosa 46.

\footnotetext{
44 Disponível em » http://freespeechdebate.com/discuss/islam-between-free-speech-and-hate-speech/« Acesso em 18 de janeiro de 2018

45 Disponível em » http://freespeechdebate.com/discuss/islam-between-free-speech-and-hate-speech/« Acesso em 18 de janeiro de 2018, p. 15

46 Sedler, Robert A. Freedom of speech: the United States versus the rest of the world. Wayne State University Law School Legal Studies Research Paper Series n. 07-21, 2006.
} 
A Suprema Corte, portanto, consolidou uma posição baseada na ampla proteção a liberdade de expressão e da democracia pluralista. Desta forma, quando resta estabelecido um conflito entre a Liberdade de expressão e a Liberdade religiosa, ambos protegidos pela Primeira Emenda, a Corte tende a privilegiar a Liberdade de expressão, baseado na ideia de que convicções religiosas profundas estão em tensão com um regime pluralista democrático.

Nos dizeres de Feldman, em uma sociedade plural e democrática os cidadãos são eivados para ter crenças, interesses e valores preexistentes, e esses interesses e valores podem ser fortemente mantidos e perseguidos, mas os cidadãos sempre devem ser capazes de acomodar os interesses e os valores dos outros, contudo, algumas crenças religiosas não são meramente fortes, são convicções - crenças imbuídas de certeza, sem dúvida. Para alguns indivíduos, tais convicções religiosas não podem ser acomodadas a outros interesses e valores na arena democrática. Neste sentido, as convicções religiosas provavelmente impedirão a discussão e negociação livre e aberta que exige a democracia pluralista47.

Não obstante a natureza quase absoluta do direito à liberdade de expressão americana, eventualmente, são reconhecidas algumas restrições ao seu exercício, que admite uma regulação do Estado sobre determinados casos, em especial, a respeito das "fighting words". As "fighting words" são reconhecidas, em geral, pela manifestação de insultos pessoais e epítetos gerais com uma perspetiva de violência imediata. As palavras altamentes suscetíveis de provocar violência são normalmente criminosas por violação das disposições de paz ou disposição desordenada48.

47 Feldman, Stephen. The theory and politics of first amendment protections: Why does the supreme court favor free expression over religious freedom? pp. 455/457. Disponível em 》 http://scholarship.law.upenn.edu/cgi/viewcontent.cgi?article=1276\&context=jcl « Acesso em 18 de janeiro de 2018.

48 “Under the Model Penal Code's section on disorderly conduct, adopted in substance by some jurisdictions, one must purposely or recklessly create a risk of "public inconvenience, annoyance or alarm" by making "offensively coarse utterance, gesture or display" or by addressing "abusive language to any person present."11 The Code also forbids harassment; one commits a violation if, with a purpose to harass, he "insults, taunts or challenges another 
No caso Chaplinsky v New Hampshire49 restou consolidado que existem certas classes de fala bem definidas e estreitamente limitadas, como as palavras obscenas, profanas, difamatórias e insultantes ou "fighting words", que por sua própria afirmação, infligem ferimento ou tendem a incitar a violação imediata da paz. Na sequência, no caso Schenck v. United States50, o juiz Oliver Holmes afirmou que é permitido ao Estado limitar palavras provocadoras desde que esteja diante de um "perigo claro e iminente" (clear and present) de um caso concreto que venha a violar um outro direito fundamental.

De todo modo, não existem palavras previamente determinadas que configurem "fighting words", restando uma análise de cada caso concreto. Neste sentido, Greenawalt sustenta que a perspetiva de uma violência imediata é uma base adequada para restringir palavras abusivas, contudo, questiona: quando esta restrição é justificada? $\mathrm{O}$ autor sugere três aspetos: os objetivos e entendimento do falante, a probabilidade de violência e a amplitude das circunstâncias em que essa probabilidade é avaliada. Ainda assim, Greenawalt reconhece que existem muitas ambiguidades sob esta base de limitação e, por fim, questiona: Quão provável que a perspetiva de violência tenha que ser para que as manifestações sejam punidas sob esta base?51

\footnotetext{
in a manner likely to provoke violent or disorderly response". Greenawalt, Kent. Fighting words, individuals, Communities and Liberties of Speech, Princeton, N.J., 1995. p. 50

49 A Doutrina da "fighting words" foi desevolvida pela Suprema Corte Americana no caso Chaplinsky v New Hampshire. USSC, Caso Chaplinsky v New Hampshire (315 U.S. 568), de 09 de março de 1942. "There are certain well-defined and narrowly limited classes of speech, the prevention and punishment of which have never been thought to raise any Constitutional problem. These include the lewd and obscene, the profane, the libelous, and the insulting or "fighting" words - those which by their very utterance inflict injury or tend to incite an immediate breach of the peace.... [S] uch utterances are no essential part of any exposition of ideas, and are of such slight social value as a step to truth that any benefit that may be derived from them is clearly outweighed by the social interest in order and morality"

50 USSC, Caso Schenck v. United States (249 U.S. 47), de 03 de março de 1919. "Words which, ordinarily and in many places, would be within the freedom of speech protected by the First Amendment may become subject to prohibition when of such a nature and used in such circumstances a to create a clear and present danger that they will bring about the substantive evils which Congress has a right to prevent. The character of every act depends upon the circumstances in which it is done. (...) the most stringent protection of free speech would not protect a man in falsely shouting fire in a theatre and causing a panic. It does not even protect a man from an injunction against uttering words that may have all the effect of force (...)".

51 Greenawalt, Kent. Fighting words, individuals, Communities and Liberties of Speech. p. 51.
} 
É possível depreender que a doutrina americana ao firmar uma ampla proteção ao direito à liberdade de expressão, estabelece uma linha resistente para reconhecer manifestações como casos de discurso do ódio. Os argumentos consistem, em suma, que se deve permitir a mais ampla manifestação de ideias, inclusive as que ofendem ou incitem o ódio, de forma a compreender a sociedade e, ainda, identificar o problema do ódio para que a sociedade possa responder e para que o governo possa tomar medidas políticas eficazes, como por exemplo para as desigualdades que afligem a sociedade52.

Além disso, sustenta-se a teoria da "slippery slope", que se baseia na ideia de que restrições à Liberdade de expressão e a proibição legal de discursos do ódio podem traduzir em efeitos contrários as necessidades das minorias estigmatizadas. Wolfson aborda sobre o risco desta teoria sob fundamento de que os tribunais tomem uma violação na neutralidade do conteúdo e no interesse da uniformidade e da coerência, desenvolvam outras violações53. Quer dizer o autor sobre o risco do extremismo das limitações, ou seja, o risco de ampliar a margem da proibição dos discursos de tal forma, que se pode chegar ao ponto de eivar a própria liberdade conquistada pela sociedade.

Neste cenário, no tocante a relação entre a Liberdade de expressão e a Liberdade religiosa, em meados das décadas de 30 e 40, o regime democrático emergente contribuiu significativamente, para o desenvolvimento de direitos e liberdades individuais. Assim, por um lado, de forma geral, as liberdades da Primeira Emenda foram revigoradas, mas, por outro lado, os juízes favoreceram a liberdade de expressão sobre a liberdade religiosa. A teoria em desenvolvimento da democracia pluralista prontamente justificou um conceito expansivo de liberdade de expressão.

Este tratamento preferencial da liberdade de expressão ainda se baseia, fundamentalmente, pelos precedentes judiciais norte-americanos. Com efeito, vale citar

52 Baker, Edwin. Hate speech, University of Pennsylvania Law School, 2008, p. 15. Disponível em »http://ssrn.com/abstract=1105043« pp. 19/20.

53 Wolfson, Nicholas. Hate speech, sex speech, free speech. Westport, Conn. 1997, p. 23 
o célere caso da Divisão de Emprego, Departamento de Recursos Humanos do Oregon v. Smith (494 US 872 (1990)), julgado pela Suprema Corte dos Estados Unidos.

Em suma, o caso abordou a questão se o Estado poderia negar os benefícios de desemprego a uma pessoa demitida pelo uso de Peyote, embora o uso da droga fosse parte de um ritual religioso. Na época, a posse intencional de peyote era um crime sob a lei do Oregon sem uma defesa afirmativa para uso religioso, tendo em vista a vedação pela Primeira Emenda da Constituição de proibir o "livre exercício" da religião. O Tribunal de Apelações de Oregon reverteu a decisão de primeira instância sob argumento de que vedar os benefícios de desemprego pelo uso religioso de Peyote violou, no caso, o direito a Liberdade religiosa. O Estado apelou ao Tribunal Supremo dos EUA, argumentando novamente que negar os benefícios de desemprego era devido porque o uso de peyote era um crime.

Por maioria dos votos a Suprema Corte arguiu que a Lei Estadual era uma "lei neutra de aplicabilidade geral". Assim, a Juíza Scalia caracterizou o argumento dos empregados como uma tentativa de usar sua motivação religiosa para usar o peyote para se colocar fora do alcance da proibição neutra e geralmente aplicável do Oregon sobre a posse de Peyote e a proteção da Primeira Emenda ao "livre exercício" da religião não permite que uma pessoa use uma motivação religiosa como motivo para não obedecer a leis geralmente aplicáveis.

Os requerentes, portanto, ponderaram se Oregon tinha um interesse convincente em proibir o uso religioso de Peyote, conforme fundamentado em decisões anteriores pela Corte54. Em resposta, a Suprema Corte argumentou que não é remotamente comparável a usá-lo para o propósito discutido no presente caso, na medida em que, nas decisões anteriores se produziu igualdade de tratamento e um fluxo irrestrito de discurso contundente, traduzindo em normas constitucionais e o que isso produziria neste caso é para justificar a preferência da Liberdade de expressão sobre outro direito fundamental. 
um direito privado de ignorar leis geralmente aplicáveis, logo, uma anomalia constitucional.

Por fim, a Corte concluiu que precisamente porque "somos uma nação cosmopolita composto de pessoas de quase todas as preferências religiosas concebíveis" e precisamente porque valorizamos e protegemos essa divergência religiosa, não podemos pagar o luxo de considerar presumidamente inválido, cada regulamento de conduta que não protege um interesse da mais alta ordem. Em outras palavras, exatamente porque a democracia pluralista se baseia na inclusão de diversos grupos sociais dentro da política americana, o direito à liberdade religiosa deve ser reduzido. Caso contrário, o Tribunal argumentou que o governo seria constrangido; quase todas as leis gerais interfeririam com as práticas ou crenças de algum grupo religioso obscuro. Esta abordagem da liberdade religiosa sugere que o seu exercício livre, tal como é interpretado, é um direito constitucional de segunda classe55.

Dentre outros casos, um mais recente, demonstra a hierarquia da Liberdade de expressão nas decisões norte-americanas, é o caso de Snyder v, Phelps at al (562 U.S_ (2011)). O caso abordou a condenação de Fred Phelps, fundador da Igreja Batista Westboro, por protestar com seus fiéis no enterro de um combatente americano da guerra, Matthew Snyder. O protesto fazia referência a crença da Igreja de que Deus odeia os Estados Unidos, pela tolerância aos homossexuais, nomeadamente, dos militares americanos, com cartazes dizendo: "Thank God for Dead Soldiers", "Fags Doom Nations" e "You're going to hell".

A ação foi proposta pelo pai do Matthew Snyder, que alegou a intenção de causar um sofrimento emocional, intrusão na vida privada, e conspiração civil. Em resposta, a Igreja afirmou que alegou que suas manifestações eram protegidas pelo direito à liberdade de expressão garantido pela Primeira Emenda da Constituição. 
Verdadeiramente, a Suprema Corte reconheceu que a Igreja estava protegida pela Primeira Emenda da Constituição e que em que pese o protesto fosse dirigido a um indivíduo em particular, a objetivo predominante dizia respeito à uma questão de interesse público, como a conduta política e moral dos Estados Unidos e seus cidadãos, o destino da nação, a homossexualidade dos militares e os escândalos envolvendo as crenças da Igreja Católica, de modo que o local da manifestação foi, unicamente, para atrair uma visão pública para tais questões.

Diante de todo exposto, é possível concluir que a tradição americana sugere uma proteção rigorosa a liberdade de expressão presumindo que qualquer discurso é protegido a menos que insira em uma categoria de expressão de baixo valor e que apresente uma violência clara e iminente. Por outro lado, a Liberdade religiosa será muitas vezes sujeita aos caprichos do processo político56, em que a reivindicação de seu exercício livre poderá ser defendida se conjugada com outra reivindicação constitucional, em particular, a liberdade de expressão.

Verdadeiramente, a solução americana para suprimir o discurso do ódio, é permitindo mais liberdade de expressão, de forma que a minoria estigmatizada participe igualmente do debate, no entanto, verdadeiramente, outros direitos fundamentais, nomeadamente, a Liberdade religiosa não recebem a mesma proteção.

\section{CONCLUSÃO}

Transcorrido o debate sobre o valor da tolerância e apresentada as teorias antagônicas defendidas pelos jusfilósofos Ronald Dworkin e Jeremy Waldron,

56 "Anyone, religious believer or not, must be disturbed by the idea of the government controlling religion to pursue a public good of egalitarian, participatory politics. (...) No subject of the human quest for understanding should become simple fodder for the government's promotion of citizenship; and the prospect of government freely manipulating religion for political ends is appalling. Only an extraordinary reversal of cultural values could lead us to think religion belongs entirely in the public political domain". Greenawalt, Kent. Fighting words, individuals, Communities and Liberties of Speech.. p. 130 
nomeadamente, sobre os limites da tolerância envolvendo a liberdade de expressão e a admissibilidade ou restrição do discurso do ódio, foi possível depreender que o grau de tolerabilidade que uma democracia liberal é capaz de suportar é alvo de duras críticas.

Para tanto, a partir da apresentação dos ordenamentos jurídicos e das jurisprudências europeia e norte-americana, o presente estudo dedicou-se a demonstrar os efeitos das limitações à liberdade de expressão e da admissibilidade do discurso do ódio contrarreligioso, na atual transição democrática.

Com efeito, vislumbrou-se o sistema europeu, em que, por meio de suas decisões, foi possível depreender que ainda há uma oscilação entre fundamentos de um regime de democracia militante e fundamentos de um regime absolutista, a depender do discurso e da legislação nacional em causa.

Ou seja, alternam entre uma posição preferencial a Liberdade de expressão, de forma que sejam admitidos todos os tipos de discursos, inclusive os que choquam, estigmatizam e ofendam, possibilitando um espaço de debates sob uma lógica de argumento e contra-argumento e entre uma posição que defende a restrição a liberdade de expressão em benefício da proteção à dignidade da pessoa humana, à moral e à honra.

Assim, conforme foi possível verificar nas decisões do TEDH, ainda não se firmou uma posição linear, clara e consolidada sobre as proibições de ofensas contra religiões e grupos religiosos, nomeadamente, para determinar quando a legislação de um determinado país ofende a CEDH. No tocante aos Estados membros, em que pese a maioria destes adotarem legislações contra casos de discursos do ódio, hodiernamente, ataques terroristas impactaram no tratamento da liberdade de expressão e da liberdade religiosa. Os ataques culminaram na adoção de rígidas medidas de segurança e vigilância o que fomentou o ressurgimento da extrema direita em toda a Europa, deixando a esquerda perigosamente dividida. Por conseguinte, esse novo panorama levantou questões complexas envolvendo os limites do exercício da liberdade de expressão e da liberdade religiosa, sobretudo, sobre a melhor forma de combater casos como a islamofobia. 
O crescimento de casos de violência antissemita e a intolerância contra demais minorias religiosas, exigem a adoção de medidas firmes para combatê-las, entretanto, uma mudança de perspetiva neste cenário deve ser adotada com cautela.

Com efeito, ainda assim, em geral, a jurisdição europeia reconhece a importância da liberdade de expressão para a formação de uma debate público aberto, livre e plural e para manutenção do Estado democrático de direito, entretanto, suas legislações e muitas de suas decisões, não reconhecem a proteção pela Liberdade de expressão às expressões contidas no discurso do ódio, de modo que ainda que o direito a liberdade de expressão seja inerente ao pluralismo político, a tolerância e a abertura de espírito, este não representa um direito absoluto.

Em sentido contrário, restou demonstrado sistema norte-americano, que defende, veemente, a manifestação das mais diversas ideias, mesmo àquelas que representem manifestações de ódio, discriminação ou ofensa para promoção de um debate totalmente livre de censura. Ou seja, a posição norte-americana assenta em uma proteção bem maior aos discursos do ódio, em face as demais democracias, concedendo uma posição preferencial à liberdade de expressão em relação aos demais direitos fundamentais, o que, verdadeiramente, atinge a dignidade da pessoa humana.

Por outro lado, os Estados Unidos admitem, em casos extremos, a restrição à liberdade de expressão, que diz respeito as "fighting words", ou seja, palavras altamente suscetíveis de provocar violência imediata, que configurem um "perigo claro e iminente" (clear and present) de um caso concreto que viole um outro direito fundamental.

Assim, esta posição demasiadamente rígida, favoreceu a liberdade de expressão sobre a liberdade religiosa. Verdadeiramente, é possível depreender que a tradição norteamericana assumiu uma doutrina praticamente intransigente no tocante a proteção preferencial da liberdade de expressão e a liberdade religiosa estará sujeita aos caprichos do processo político, em que a pretensão de seu exercício livre só poderá ser defendida 
se conjugada com outra pretensão constitucional, nomeadamente, a liberdade de expressão.

A solução americana para suprimir o discurso do ódio contrarreligioso, é propiciando mais liberdade de expressão, para que os indivíduos estigmatizados participem, da mesma forma, no debate, e façam prevalecer suas ideias e opiniões. Porém, verdadeiramente, a Liberdade religiosa não recebe a mesma proteção.

Por todo exposto, restou demonstrado que as configurações dos limites entre a liberdade de expressão e a liberdade religiosa exigem um rigoroso trabalho de campo e de pesquisa teórica, definindo, para tanto, as linhas entre críticas e insultos, o que varia entre as ordens jurídicas e a cultura.

A regulação do discurso do ódio contrarreligioso não é incompatível com o sistema democrático, pois mina o exercício extremo da liberdade de expressão que atinja demais direitos fundamentais e promova a intolerância contra minorias. No entanto, este trabalho deve ser realizado de forma extremamente cautelosa, sob pena de que a nova liberdade se volte para a velha censura.

Restou evidente que delimitar uma linha entre discursos permitidos ou proibidos, não se mostra uma tarefa fácil, principalmente, pelas diferentes interpretações e contextos culturais, sociais, históricos e políticos que se inserem. Não obstante, o atual contexto democrático exige, cada vez mais, uma revisão deste cenário, para que alcance uma diretriz.

De todo modo, enquanto, por um lado, se exige uma atuação estatal que regule o discurso do ódio, tal desenvolvimento só será possível a partir da formação de uma sociedade tolerante, que respeite às crenças religiosas, o multiculturalismo, o pluralismo e o respeito mútuo às diferenças e, concomitantemente, à liberdade de expressão.

\section{REFERÊNCIAS}

BAKER, Edwin. Hate speech, University of Pennsylvania Law School, 2008. 
BAKIRCIOLGLU, Onder. Freedom of Expression and Hate Speech. Heinonline, 16 Tulsa. J. Comp.\& Int’1 L. 2008.

BOBBIO, Norberto. A Era dos Direitos. Trad. Carlos Nelson Coutinho. Rio de Janeiro: Elsevier, 2004.

DONAIRE, Juan Antonio Carrillo. Libertad de expresión y "discurso del odio" religioso: la construcción de la tolerancia en la era postsecular. Revista de Fomento Social 70. 2015.

DWORKIN, Ronald. Foreword to Extreme Speech and Democracy. In: Hare, Ivan. Extreme Speech and Democracy, New York: Oxford University Press, 2009.

DWORKIN, Ronald. Uma questão de princípio. Trad. Luis C. Borges. São Paulo: Martins Fontes, 2001.

FELDMAN, Stephen. The theory and politics of first amendment protections: Why does the supreme court favor free expression over religious freedom?

GREENAWALT, Kent. Fighting words, individuals, Communities and Liberties of Speech, Princeton, N.J., 1995.

GUEVONTIAN, Richard. Direitos humanos fundamentais. In. Encontro de Direito Constitucional, 2004, XIII, Anais.São Paulo: Instituto Pimenta Bueno, 2004.

LAWRENCE III, Charles R. If he hollers let him go: Regulating Racist speech on Campus, Duke Law, Journal 1990. In: Words that Wound: Critical Race Theory, Assaultive Speech and the First Amendment, Mari J. Matsuda, Charles R. Lawrence III, Richard Delgado \& Kimberlé Williams Creenshaw. Westwiew Press, 1993.

LOEWENSTEIN, Karl. Militant democracy and fundamental rights. The American Political Science Review 31, n. 3, 1937.

MACHADO, Jónatas, Liberdade de expressão. Dimensões constitucionais da esfera pública no sistema social. Boletim da Faculdade de Direito, Studia Iuridica 65. Coimbra Editora: Coimbra. 2002.

MEYER-PFLUG, Samantha Ribeiro. Liberdade de expressão e discurso do ódio. São Paulo: Editora Revista dos Tribunais, 2009.

SANNA, Júlia Mestres. La Islamofobia en Europa y en el Estado español: Repercusiones en el ejercicio del derecho fundamental a la libertad religiosa, 2017. 
SCALON, Tim. The difficulty of tolerance: Essays in political philosophy, Cambridge: Cambridge University Press, 2003.

SEDLER, Robert A. Freedom of speech: the United States versus the rest of the world. Wayne State University Law School Legal Studies Research Paper Series nº. 07-21, 2006

STSJ ISLAS BALEARES, (Sala de lo Social, Sección1ª) núm. 457 de 9 de setembro de 2002

SUPREMA CORTE DOS ESTADOS UNIDOS, Caso Chaplinsky v New Hampshire.

Caso Divisão de Emprego,

Departamento de Recursos Humanos do Oregon v. Smith (494 US 872 (1990))

\section{Caso Schenck v. United States (249}

U.S. 47), de 03 de março de 1919.

Caso Snyder v, Phelps at al (562 U.S

(2011)).

TITLEY, Gavan; MONDON, Aurélien. After Charlie Hebdo: Terror, Racism and Free Speech. Zed Books, 2017.

TRIBUNAL EUROPEU DOS DIREITOS DO HOMEM, Caso Belkacem v. Belgium (App. No. 34367/14), de 27 de junho de 2017.

. Caso Erbakan v. Turkey

(App, no. 59405/00), de 06 de Julho de 2006.

Caso Gündüz v. Turquia

(App. $\left.n^{\circ} .35071 / 97\right)$, de 04 de junho de 2004.

Caso Handyside v. Reino

Unido (App. $n^{\circ} .5493 / 72$ ), de 07 de Dezembro de 1976.

Caso Ivanov v. Russia

(App. n. 35222/04), de 20 Fevereiro de 2007.

Caso Norwood v. the

United Kingdom (App. no. 23131/03), de 16 de novembro de 2004. 
Caso S.A.S. v. França (App. $n^{\circ} .43835 / 11$ ), de 01 de julho de 2014, venice commission, On the relationship between freedom of expression and freedom of religion: the issue of regulation and prosecution of blasphemy, religious insult and incitement to religious hatred, outubro de 2008.

WALDRON, Jeremy. The harm in hate speech. Cambridge: Harvard University Press, 2012.

WOLFSON, Nicholas. Hate speech, sex speech, free speech. Westport, Conn. 1997

Data da submissão: 02/02/2020

Data da primeira avaliação: $30 / 04 / 2020$

Data da segunda avaliação: 06/05/2020

Data da aprovação: 06/05/2020 